\title{
LOS ESTUDIOS SOBRE LA ADMINISTRACION PUBLICA: LA NECESIDAD DE CONSTRUIR UNA DISCIPLINA QUE SEA LA BASE FORMATIVA DE UNA CLASE DIRECTIVA PROFESIONALIZADA
}

\section{Por ALEJANDRO NIETO}

Catedrático de Derecho Administrativo en la Universidad de Alcalá de Henares

Sumario: 1. PLANTEAMIENTO.-II. EN BUSCA DE LOS ORIGENES: 1. El sentido de los origenes de la Ciencia de la Administración de Europa y de España. 2. Edad Moderna. 3. Siglo XIX. 4. La irrupción de las teorias norteamericanas. 5. Situación actual.-III. EN BUSCA DE LA DIFICIL IDENTIDAD: 1. El contenido: administración pública y organizaciones privadas. 2. Los instrumentos.-IV. CLASIFICACION DE OBJETIVOS.-V. FORMACION DE DIRECTIVOS.

\section{PLANTEAMIENTO}

El enunciado del tema, que se me ha propuesto, da por supuesta la existencia de una disciplina (los estudios de la Administración Pública) que todavía no existe en España o que, al menos, caso de existir, no sirve para la formación de directivos; y presupone igualmente la conveniencia -e incluso la necesidad- de construirla con esta específica finalidad. El desarrollo de tales ideas obliga, por tanto, a dar un repaso al estado de esa Ciencia de la Administración, tan ordinariamente invocada como mal conocida: una tarea ingrata, puesto que obliga a repetir cosas mil veces descritas por quienes se han preocupado del tema; pero que resulta de todo punto imprescindible, dado que, como veremos inmediatamente, el conocimiento preciso de la situación actual (aunque sea dando un rodeo a través de sus antecedentes históricos) es la única forma de aclarar la funcionalidad y sentido de dicha disciplina. 
DA-1984, núm. 200. ALEJANDRO NIETO GARCIA. Los estudios sobre la Administración Pública: I...

Estudios

Pocas ciencias se encuentran afectadas ciertamente por un confusionismo similar al que envuelve la llamada Ciencia de la Administración, de la que se cuestiona no ya sólo su consideración de ciencia (lo que en el fondo resulta bastante académico y a nuestro propósito escasamente interesante) sino su contenido y finalidad y hasta su propia existencia como disciplina única: circunstancia que obliga a los más cautelosos a utilizar una denominación en plural, que a nada compromete.

$Y$, sin embargo, la cuestión no es nada dificil cuando se examinan sus antecedentes históricos que, por muy prolijos que parezcan, nos demuestran que desde siempre (incluso, si se quiere, desde la Edad Media) ha habido una preocupación por el arte de administrar y un interés en impartir su conocimiento a los futuros administradores. Lo que sucede es que en ocasiones se confunde este arte, y su correspondiente enseñanza, con la Ciencia del Derecho, que desde la privilegiada plataforma de las Universidades, recaba para si un auténtico monopolio en la formación de lo que hoy llamariamos empleados públicos de alto nivel o clase directiva. No obstante, un mínimo análisis histórico descubre fácilmente la falta de identificación de ambos conocimientos y de su práctica. De aqui la inexcusabilidad del examen de una evolución histórica, mucho más sencilla y mucho menos azarosa de lo que se piensa, puesto que resulta siempre coherente consigo misma y con su entorno cultural y social.

Pero tambiẻn ha sucedido, por otro lado, que esta linea evolutiva, aceptablemente rectilinea, se ha quebrado desde principios del siglo por la irrupción del pensamiento norteamericano, que ya no es coherente con todo lo anterior, puesto que ha nacido libre de la tradición europea, pero que se inserta en ella, provocando una doble y contradictoria reacción, que es la causa del confusionismo denunciado. Porque en parte es aceptado con un entusiasmo no exento de lo que podria denominarse papanatismo; y en parte es rechazado en cuanto que el tejido cultural europeo no lo soporta. $Y$ asi es como se ha formado un pensamiento hibrido, profundamente ambiguo.

Debidamente separados estos dos elementos, se gana una enorme claridad y los países que han sabido imponer una rigurosa barrera intelectual no tienen los problemas que acongojan a los españoles. Si observamos la bibliografia francesa, por ejemplo, podremos sentirnos seducidos por ella, o no; pero lo que es indudable es que ofrece un bloque muy homogéneo de conocimientos: es una línea recta que (refiriéndonos a los últimos años) arranca en Gournay: Introduction $\dot{a}$ 
DA-1984, núm. 200. ALEJANDRO NIETO GARCIA. Los estudios sobre la Administración Pública: I...

la science administrative, 1966, y pasando por Langrod: Traité de science administrative, 1966; Debbasch: Science administrative, 1971; Drago: Science administrative, 1972; Lalumière: Science administrative, 1975, y Catherine y Thuillier: Science administrative, 1974, llega sin solución de continuidad a Chevallier y Loschak: Science administrative, 1978. Todas estas obras responden a un esfuerzo integrador .del pensamiento administrativo francés, que se va liberando poco a poco de las servidumbres juridicas tradicionales del Derecho Administrativo y que se confiesa tributario de sus antecedentes históricos genuinos; lo que no le impide rechazar, antes al contrario, las aportaciones de la ciencia trasatlántica, en la medida en que sus resultados $y$, sobre todo, sus técnicas han sido aceptadas por las monografias francesas sobre las que se construyen estas obras generales.

Bien es verdad que, en cuanto a su contenido, la ciencia administrativa francesa no parece espectacular ni puede considerarse un modelo de precisa imitación en otros paises europeos; pero su nivel no es desdeñable y su utilidad, teórica y práctica, es palmaria. $Y$, en cualquier caso, lo que aqui importaba era recoger su actitud intelectual. En el epígrafe II se describen las líneas evolutivas de la Ciencia de la Administración, de acuerdo con lo que acaba de indicarse.

Con la depuración de estos dos troncos -el europeo y el americanono se ha hecho, sin embargo, más que dar el primer paso. Porque a continuación viene el gran tema de precisar el contenido de esa ciencia, cualesquiera que sean sus contornos concretos. La familia europea, abrumada un poco por la influencia americana, apenas si acierta a concretar sus objetivos y lucha por encontrar un lugar en el mundo de las ciencias y por tener acogida en las Universidades. Padece, de alguna manera, un cierto complejo de inferioridad tanto en relación con las ciencias universitarias como por referencia a la Ciencia administrativa norteamericana, a la que se supone comparativamente mucho más desarrollada y provista de un status cultural indiscutido.

$Y$, sin embargo, las diferencias entre las dos familias no son tan importantes. Porque los americanos se han percatado últimamente de que su Ciencia de la Administración también está atravesando una crisis de identidad, de la que no acierta a salir. Con lo cual desembocamos inevitablemente en el agotador debate sobre la naturaleza, contenido y significado de esta Ciencia tan agresiva y, al tiempo, tan débil. Cuestión que es examinada en el epigrafe III. 
Para encontrar una solución operativa, a los efectos del presente artículo, se profundiza, en el epígrafe IV, en los posibles y constatados objetivos de la Ciencia de la Administración, entre los que se encuentra el de la formación de directivos, que es nuestro tema propiamente dicho, y al que se dedica, con cierta minuciosidad, el epigrafe $\mathrm{V}$.

La Ciencia de la Administración (que ya ha sido histórica y conceptualmente depurada en los epigrafes anteriores) nos ofrece ahora, entre otros objetivos, el de la formación de las clases directivas de la Administración Pública. Afirmación que nos conduce al análisis de las posibilidades reales que en la situación española actual existen. Dicho con otras palabras: en último extremo se trata de sugerir fórmulas concretas de implantación de esta idea, habida cuenta de que no importa solo "construir una disciplina» sino determinar quien va a construirla, y dónde, y sobre todo de qué manera puede institucionalizarse en la España de hoy la creción y enseñanza de esa ciencia a efectos de la formación de una clase directiva profesionalizada de la Administración Pública.

\section{EN BUSCA DE LOS ORIGENES}

1. El sentido de los origenes de la Ciencia de la Administración de Europa y de España.

El español que quiere estudiar sinceramente la Administración Pública se encuentra en la mayor de las perplejidades. En las carreras universitarias (y no sólo en las Facultades de Derecho) se estudia el tema con cierta minuciosidad; pero a poco que quiera profundizar en él, llega pronto al convencimiento que la perspectiva juridica apenas si roza la superficie de las cosas y adquiere inevitablemente la sensación -por lo demás, muy justa- de que no tiene acceso al verdadero núcleo de los problemas. El Derecho Administrativo le enseña, en efecto, cómo puede defenderse el ciudadano contra las agresiones del Poder público; pero nada, o casi nada, le dice sobre cómo tiene que actuar la Administración para ser mínimamente eficiente y para responder de manera eficaz a las exigencias sociales. Para el Derecho la Administración es un mero aparato formal, atento sólo a la legalidad de sus actividades, no al contenido de ellas ni mucho menos a su realidad. 
DA-1984, núm. 200. ALEJANDRO NIETO GARCIA. Los estudios sobre la Administración Pública: I...

Estudios

Con este bagaje, debidamente memorizado, se adquiere la condición de funcionario, para comprobar inmediatamente el abismo que separa el Derecho del arte de administrar. Un arte que, al parecer, sólo puede adquirirse con los años de la práctica, que con frecuencia resultan, además, estériles, por cuanto la práctica es inerte por sî misma, cuando no va acompañada de una reflexión teórica.

La desconexión que en España existe entre la formación cientificouniversitaria de los estudiantes y la experiencia que posteriormente adquiren los funcionarios, es sencillamente escandalosa y supone un despilfarro social, tanto para los individuos como para la propia Administración.

Para cubrir de alguna manera este bache aparece la llamada Ciencia de la Administración, deus ex machina que pretende resolver el problema con la autoridad y el prestigio de unos precedentes extranjeros, y particularmente norteamericanos, que se magnifican ideológicamente. Pero sucede que en la realidad, cuando el estudiante acude afanoso a esta Ciencia pregonada, no la encuentra por ninguna parte. En todas las Universidades españolas sólo hay una cátedra con este nombre, la bibliografia es extranjera y tan contradictoria, que, según haya sido traducida del inglés o del francés, parece que se está refiriendo a cuestiones totalmente distintas. En la literatura española sólo se publican interminables debates sobre la naturaleza de la ciencia, que suelen acabar con la afirmación de que su objetivo es el estudio de la Administración pública desde una perspectiva no juridica, sin que llegue nunca a entrarse en ese estudio. Y cuando el afán del saber aproxima al curioso a los lugares donde se enseña la administración privada, resulta casi imposible determinar si este tipo de conocimientos tienen alguna relación con la Administración pública y con las tareas de sus directivos.

La desazón del estudiante está, pues, más que justificada. Estamos casi en el punto cero, y quizás aún peor, puesto que se necesita mucha energía para atravesar el caparazón de las interminables controversias doctrinales a que acaba de aludirse.

Importa, pues, tomar conciencia de nuestro estado y afrontarlo con modestia, porque sólo asi se podrá caminar sobre seguro, sin meterse en aventuras decepcionantes. Importa igualmente construir una Ciencia de la Administración inequívocamente española y ello, no al amparo de nacionalismos trasnochados, sino por tratarse de una Ciencia cuyo objeto es una realidad social muy concreta, a la que hay que atenerse. 
DA-1984, núm. 200. ALEJANDRO NIETO GARCIA. Los estudios sobre la Administración Pública: I...

Estudios

Las matemáticas son un ciencia universal y, con algunas reservas, también lo es la medicina. Pero desde el momento en que el objeto de la Ciencia de la Administración es una Administración Pública concreta (la española), la Ciencia tiene que ser también española.

Lo cual no significa, naturalmente, la marginación de técnicas instrumentales procedentes de cualquier país, pues ello significaria una tibetanización mortal. Los científicos españoles que estudian la oveja churra o las marismas del Guadalquivir se han formado indefectiblemente en Universidades extranjeras y utilizan técnicas universales, sin perjuicio del «españolismo» de su actividad. Esta es la única forma del progreso; aunque, por lo mismo, resultaria grotesco que actuaran en la misma manera que sus colegas daneses cuando éstos se ocupan de la ganadería de los pastizales húmedos del norte de Europa.

Se trata, por tanto, de aproximarse a un fenómeno español con técnicas, que pueden ser universales. Y se trata, también de, partiendo de una Ciencia española de la Administración, formar a la clase directiva de la Administración pública española. Con tales datos resulta inevitable, en consecuencia, tener que rastrear los origenes de la Ciencia, para encontrar un punto de referencia que clarifique de algún modo el confusionismo, al que antes se ha aludido. Cuando se ha perdido la identidad, el mejor modo de encontrarsela consiste en reflexionar sobre las causas que han provocado la situación que se padece. Hay que clarificarse sobre lo que ha sido la Ciencia de la Administración europea y española. Porque, logrado ésto, se van a despejar por sí mismos muchos problemas innecesarios.

A esta tarea, aparentemente enojosa en cuanto repetitiva, va a dedicarse el presente epigrafe, que convencionalmente se inicia en la Edad Moderna y con la Ciencia de la Policía. Pero si se prescinde de la. Edad Media es por razones de sobriedad expositiva, no porque en esta época se carezcan de testimonios adecuados. La Ciencia de la Administración, concebida como reflexión sobre el arte de administrar, acompaña a las organizaciones sociales como la sombra al cuerpo. Por ello, la historia de esta ciencia es la historia de una evolución adaptativa a las exigencias de cada época. En unos momentos se llamará cameralista o policia o management, pero su identidad substancial se conserva inalterable.

Las Partidas medievales, por ejemplo, no son una mera norma jurídica (su validęz normativa es muy posterior a su publicación) sino un conjunto de reglas o consejos para todas las ramas de la administra- 
ción, incluida la de justicia. Nadie puede discutir, por ello, que se trata de un Tratado de Ciencia de la Administración, y de los más completos y perfectos que se conocen; aunque su apariencia normativa, y su posterior adquisición de rango legal, hayan enturbiado su carácter originario. $Y$ si se quiere otro testimonio más convencional, más doctrinal, puede acudirse a la «Suma de la politica, que fabla cómo deuen ser fundadas e edificadas las cibdades e uillas -fabla otrosí del buen regimiento e recta polecía que deue auer todo reyno o cibdad assi en tiempo de paz como de guerra», que escribe en el siglo xv Rodrigo Sánchez de Arévalo (ed. de Beneyto, 1944). Pero, tal como se ha indicado antes, se va a prescindir de la época, que nos llevaría demasidado lejos en el tiempo y en la erudición inútil.

Con lo dicho basta y con una última indicación: a mi juicio, el primer tratado de ciencia de la administración (si vale esta traspolación terminológica) es, sin duda, el Dialogus de scaccario, que escribe jen el siglo XII! Ricardus de Ely (ed. de Siegrist, Zürich y Stuttgart, 1963). Durante la Edad Media, como en los siglos posteriores y en la actualidad, los altos funcionarios proceden de las Universidades y su formación es predominantemente juridica; pero, tal como acabamos de ver, esta formación resulta insuficiente y las mentes más lúcidas se ocupan de reflexionar sobre la Administración, aunque su esfuerzo resultara anegado por la presión universitaria, en gran medida oficialista e inútil.

\section{Edad Moderna}

La solución de la sociedad estamental, propia de la Edad Media, y el consiguiente fortalecimiento del Estado, habian de cambiar radicalmente el panorama anterior. El poder monárquico necesita ahora de una Administración eficiente, que desbordaba las rudimentarias estructuras que se habian ido formando lentamente en la Baja Edad Media, $y$, sobre todo, se produce una diversificación del aparato: la gestión del patrimonio de Corona continúa relativamente estancado, mientras que la Administración real (lo que hoy llamariamos Administración del Estado) experimenta un desarrollo espectacular, que gira sobre un Ejèrcito, cada día más profesionalizado y «real», el cual precisa de unas finanzas robustas $y$, en último extremo, de un aparato administrativo fuerte, que se ocupa también -aunque quizás indirectamente- del bienestar de los súbditos, en cuanto que sin tal bienestar nơ es posible 
DA-1984, núm. 200. ALEJANDRO NIETO GARCIA. Los estudios sobre la Administración Pública: I...

ni la riqueza del monarca ni la fortaleza de su ejército. A lo que hay que añadir, en fin, las organizaciones propias de las monarquias «imperialistas», extraterritoriales y coloniales, que se van afirmando durante esta època.

\subsection{Alemania.}

El caso alemán suele ser tenido en cuenta como paradigmático. La Monarquia prusiana, aún más que el Imperio, se organiza con un estilo moderno, utilizando el instrumento de funcionarios especializados, a los que se quiere dar una formación científica adecuada, para la que resultan notoriamente insuficientes los meros estudios jurídicos. Federico Guillermo I da la voz de alarma con su autoridad y en los rudos tonos, que le son propios: los juristas, «que hasta ahora sólo han aprendido cosas inútiles y rabulismos de abogado, deben orientarse hacia los temas políticos, económicos y cameralisticos». Tal es la consigna, válida para toda Europa, que corona una evolución intelectual y formativa, que ya se habia iniciado muchos años antes.

A tal efecto, se crean cátedras de Cameralística en las Universidades: primero en la de Halle, en 1723; y luego en la de Frankfurt del Oder, en 1727 , a las que siguen otras. $Y$ por si esto fuera poco, se crean igualmente Escuelas especiales para la formación de funcionarios, como las de Lautern y Stuttgart.

La materia cientifica es proporcionada por una abundante literatura, que se conoce con el nombre de «ciencia cameral y de policia», que alcanza pronto un brillo inusitado, desprendiéndose al punto del tronco común del Derecho Público en que inicialmente había aparecido (como puede apreciarse todavia en la obra del iuspublicista Thomasius). Austriacos y prusianos producen durante todo el siglo una bibliografia abrumadora, que desborda las obras del predecesor von Seckendorff (1656): J. Ch. Dithmar (1731), J. H. G. von Justi (1755-1756), J. von Sonnenfels (1763-1767), G. von Berg (1799-1806).

\subsection{Francia.}

Rigurosamente contemporánea es la aparición en Francia de la Ciencia de la Policia, cuyo representante más insigne es Nicolás Delamare, que publica entre 1705 y 1710 un monumental Tratado de 
Policia, a la que seguirian numerosos Códigos de Policia, en los que se pretende sistematizar la variada actividad del Estado y de sus instrumentos.

Pero esta Ciencia de la Policia, ni entra en las Universidades ni sirve realmente para la formación de funcionarios. Las Universidades siguen su propio ritmo y, desde luego, no son insensibles a las necesidades administrativas del momento, como lo prueba el Derecho Público de Domat, estrechamente enraizado ya en el Derecho francés y en las necesidades de su Administración. Hasta tal punto es esto cierto que, al menos desde la perspectiva de hoy, el libro de Domat había de ser mucho más útil a los funcionarios de cierto nivel que el de Delamare.

\subsection{ESPAÑa.}

España entra en la Edad Moderna satisfaciendo su demanda de funcionarios reales a través de las Universidades. «Los buenos empleos de la burocracia española -escriben Mariano y José Luis Peset: La Universidad española. Siglos XVIII y XIX, 1974, p. 284- recaian fundamentalmente entre los graduados de las tres Universidades mayores; muchos y muy sustanciosos entre los colegiales. Los consejos reales, las audiencias y las chancillerias se nutren de estas procedencias. Los manteistas tenían más dificultades en sus ascensos y carrera. Pero, en conjunto, la nobleza baja de hidalgos encontraria en la toga acertado cauce para la elevación de muchos de sus individuos; la alta, con mayor facilidad, pues 'podía ascender por su dignidad, como letrados o ministros de capa y espada de la alta burocracia española. En general, siempre había hueco para el jurista de talento, mientras le acompañase la suerte y el favon.

Pero, al igual que ya hemos visto habia sido denunciado en Alemania, resulta notorio que la formación jurídica que estos letrados reciben en las Universidades, parece insuficiente e inadecuada. Lanz de Casafonda (citado por los hermanos Peset en el lugar indicado) advierte de ello en el siglo XVIII: «Provéense las Audiencias (desde donde por sus pasos contados vienen a parar a los Consejos que tiene el Rey en su Corte) de colegiales mozos, sin ciencia ni experiencia de negocios y sin haber estudiado la Jurisprudencia práctica, teniendo sólo cuando salen de los Colegios una escasa y superficial noticia del Derecho de los Romanos, que estudian sin orden ni método $(y)$ sin haber estudiado las Leyes del Reino». 
DA-1984, núm. 200. ALEJANDRO NIETO GARCIA. Los estudios sobre la Administràción Pública: I...

$Y$, sin embargo, se contaba en España, a tales efectos, con una obra fundamental, mucho más antigua, sistemática y formativa que la de Delamare: la Politica de Corregidores y Señores de Vasallos de Castillo de Bobadilla, publicada en 1595 y de la que aparecen sucesivas ediciones hasta finales del siglo xviII. Por descontado, que no va a entrarse aquí en estériles discusiones sobre valores y primacias comparativás -ahí están los libros y enjuicie cada lector-; pero es muy significativo que la obra de Castillo de Bobadilla, inequívoco tratado de Ciencia de la Policia, se publique en una época mucho más temprana que la de sus correlativos europeos. Lo que sucede es que aquí no encuentra continuadores ni gobernantes que reflexionen sobre su significado. Los epílogos de Castillo son tardios e insignificantes $y$, cuando renace la Ciencia de la Policia a fines del siglo xviII Foronda lo hace bajo el signo de la improvisión o de la influencia francesa, cuando ya la importancia de esta ciencia está decayendo en toda Europa.

Por otro lado, en España, al igual que en Francia, el Derecho Público, aunque deliberadamente no se entronca con la Ciencia de la Policia, tampoco se mantiene insensible a las necesidades de la Administración Pública concreta, a la que se va aproximando gradualmente, con un correlativo alejamiento del Derecho romano y del natural. Hitos de este proceso podrian ser: el Apparatus iuris publici hispanici, 1751, de Pedro José Pérez Valiente, las Instituciones del Derecho Civil de Castilla, 1771, de Ignacio Jordán de Asso y Miguel de Manuel y Rodríguez, la Ilustración del Derecho Real de España, 1803, de Juan Sala y, sobre todo, las magistrales Instituciones de Derecho Público general de España, con noticias del particular de Cataluña, 1800-1803, de Ramón L. de Dou y Bassols.

Todas estas obras pretenden tecnificar la formación $-\mathrm{y}$, en su caso, el ejercicio- de los servidores de la Corona, cuyo paso por la Universidad realmente les habia servido de muy poco desde el punto de vista de la capacitación profesional. La creación de un grupo de juristas, apto para servir las necesidades del nuevo Estado, había sido consecuencia de un planteamiento predominantemente político: la Corona pretende liberarse de la dependencia de los nobles y aspira a constituir una clase intelectual más dependiente de ella (o si se quiere de las instituciones), provista de unos conocimientos que sólo podía proporcionar la Universidad. Ahora bien, el intento resulta un estrepitoso fracaso, no tanto por la insuficiencia de los estudios del Derecho que se impartian en la Universidad como por el contexto politico: la 
nobleza, empobrecida por la evolución social, comprende la rentabilidad, política y económica, que puede proporcionar el servicio real y se enrola en él con tanto entusiamo que desplaza a los burgueses. Y como para ello era imprescindible, de acuerdo con el esquema inicial, haber seguido determinados estudios, acude a la Universidad. Pero, una vez fuera de ella, los burgueses o la baja nobleza no puede resitir la competencia de los juristas nobles y queda relegada a un segundo término, ocupando -salvo excepciones- los puestos inferiores, que la nobleza desprecia. De esta forma, el sistema no funciona, puesto que los nobles siguen monopolizando el poder, siquiera lo hagan ahora con un pequeño barniz jurídico $\mathrm{y}$, al menos formalmente, no por su condición de nobles sino por la de letrados. Pero es claro que lo que se impone son las relaciones personales, y no los conocimientos personales de los candidatos. La nobleza en el poder se perpetúa, puesto que coopta a los altos cargos únicamente entre sus miembros.

Las modernas investigaciones, tanto ideológicas como de mensuraciones cuantitativas, no dejan duda al respecto: los altos cargos de la política y de la Administración están reservados a los letrados nobles, que siguen siendo así el mejor apoyo de la Corona. Y ésta, por su parte, favoreciendo el viejo pacto (ahora renovado en los términos que se ha dicho), tranquiliza su conciencia pensando que son técnicos estos nobles que le asisten. La realidad, sin embargo, es muy otra y así se explica la baja calidad del funcionariado superior y, en definitiva, el fracaso de una burocracia modernizada formalmente, pero que seguia nutriéndose por impulsos e intereses estamentales. Esta idea, apuntada ya por Vicens Vives y Maravall y aceptada por los historiadores, ha encontrado su rotunda prueba documental en estudios especializados como los de Kagan: Students and Society in Early Modern Spain, 1974, y Fayard: Les membres du Conseil de Castelle a'époque moderne, 1979, y es la tesis central de los trabajos de Pelorson: Les letrados, juristes catillans sous Philippe III, 1980, y de Dámaso de Lario: Sobre los origenes del burócrata moderno, 1980; sin que sea necesario aportar otros testimonios bibliográficos, que en la actualidad ya son más que suficientes.

En el siglo xviI este fracaso ya no puede ocultarse y la tecnificación bibliográfica y universitaria, que por entonces tiene lugar, es un intento de provocar una nueva renovación, ahora más sincera. La elevación del nivel de estudios era la única forma de desestimular a los nobles que no estuvieran bien dotados intelectualmente o que carecieran de una 
DA-1984, núm. 200. ALEJANDRO NIETO GARCIA. Los estudios sobre la Administración Pública: I...

auténtica vocación de servicio. En último extremo lo que se pretendía -aunque quizás de una forma no deliberada- era facilitar el acceso al poder de los estudiantes no nobles o, si se quiere, de los burgueses.

Un proceso que, acelerado en el siglo xvill no se consolidaria hasta el XIX; pero entoces no por las causas técnicas aparentes, a que estamos aludiendo, sino por razones predominantemente políticas. No es la capacitación profesional la que abre las puertas de la Administración a los burgueses, sino la revolución liberal.

\section{Siglo XIX.}

La evolución de las ciencias administrativas experimenta en toda Europa un giro radical a principios del siglo xIX con determinados rasgos comunes a todos los paises. Pero, sin desconocer este factor, no es menos cierto que las peculiaridades nacionales, que inciden, son tan fuertes, que conviene seguir insistiendo en un tratamiento separado.

\subsection{Alemania.}

La ciencia alemana experimenta a primeros del siglo una renovación tan radical, que en gran medida rompe con su vieja tradición dieciochesca. Los nombres de Fichte, Schleiermacher y von Humboldt introducen en Berlín una figura universitaria, que habría de resultar decisiva por mucho tiempo. La Universidad se desprende de su carácter utilitario para convertirse en la formadora de hombres de signo liberal y humanistico, abierto a la mentalidad de una nueva época.

Aunque sólo fuera por ello, venía a hacerse ya incompatible con la cameralística, vinculada a otro estilo de Estado y de sus funcionarios. Pero, además, la especialización que iba produciendo el simultáneo progreso de las ciencias, provocaba la separación, o «autonomía» de antiguas ramas, que todavia en el siglo anterior habian podido vivir unidas. Tal es caso de la cameralística, cuyo tronco -básico e inicialla economia, se transforma en la «economía política».

Pero todavía mucho más importante que esto, es la evolución ideológica: el liberalismo del siglo que comienza, limita los objetivos del Estado a la garantía o protección de la seguridad y el orden de los fenómenos sociales, cuya vida pretende independizarse de aquel. En estas circunstancias era claro que la cameralística y la ciencia de la 
policía -rigurosamente antitéticas con las nuevas ideas- estaban condenadas a muerte.

De esta forma el Derecho se convierte en la ciencia nuclear del Estado, puesto que son técnicas juridicas las que articulan la protección de los ciudadanos frente a un Estado, al que se quiere limitar a círculos muy estrictos. Y el Derecho -el fenómeno no es causal- se aborda desde la perspectiva del «método jurídico», que si, por una parte, le permite un progreso y una precisión espectacular, por otro le separa inexorablemente de la Administración, entendida ahora como la zona del Estado, que comprende actividades no jurisdiccionales (ni legislativas).

La tradición cameralística no sólo es desalojada sin piedad de las Universidades sino que se pierde en muy pocos años, puesto que ni a los estudiantes, ni tampoco a los funcionarios, interesa el tema. En su lugar, reaparece con toda su fuerza el Derecho Público o, mejor todavía, el Derecho del Estado, en cuyo seno se inserta el Derecho Administrativo, que, en definitiva, es «derecho», aunque venga modulado por la calificación de «administrativo».

$Y$, sin embargo, la Ciencia de la Administración no desaparece del todo, puesto que encuentra cultivadores de talla excepcional, cuya influencia sigue siendo viva hasta en la actualidad: Robert von Mohl (Polizeiwissenschaft nach den Grundsaetzen des Rechtsstaates, 1832) y Lorenz von Stein (Verwaltungslehre, 1865-1868). Pero la originalidad de estos autores consiste no tanto en el contenido de sus obras como en su actitud, que responde a un esfuerzo genial para adaptarse a la ideología de su tiempo. La nueva Teoria de la Administración no supone, por tanto, una mera renovación técnica sino una revolución al tiempo científica y política. Ambos se percatan de que la cameralistica es incompatible con las ideologías dominantes en el siglo XIX y lo que pretenden es adaptar la ciencia a las necesidades del tiempo. El objetivo confesado de von Mohl consiste en el examen de las posibilidades de actuación de la Administración en cuanto brazo ejecutivo del Estado liberal. Mientras que von Stein se centra en el análisis de la receptividad administrativa a los «movimientos sociales», que para él son las claves de la evolución, no sólo de la sociedad, sino de todas las instituciones.

Pero sin desconocer la importancia de estos autores, es evidente que su influencia no ha sido bastante como para frenar el progresivo monopolio del Derecho y -a partir de la segunda mitad del siglo del Derecho Administrativo- sobre los temas constantes de la Administración Pública. Hasta tal punto que en visperas de la guerra europea la 
DA-1984, núm. 200. ALEJANDRO NIETO GARCIA. Los estudios sobre la Administración Pública: I...

cameralista y en gran parte también la Teoria de la Administración es poco más que un recuerdo, piadosamente conservado por los tratadistas del Derecho Administrativo.

\subsection{Francia}

Al igual que sucede en Alemania, tambièn cambia en Francia por completo el panorama científico al comenzar el siglo XIX. Los estudios de la policia, harto debilitados ya, se ven sustituidos por los del Derecho Administrativo, aunque durante las primeras décadas del siglo se aprecia una actitud vacilante: los autores, juristas por profesión, son perfectamente conscientes de la insuficiencia del Derecho $-y$ más, tratándose de una disciplina todavía rudimentaria- a los efectos de la comprensión del fenómeno administrativo y hablan, con mayor propiedad, de Ciencia de la Administración, que en su pluma toma carta de naturaleza en la bibliografia europea.

Ya en la época del Imperio inicia Bonnin este camino de forma explícita y sus huellas son seguidas por Macarel y Vivien (que tanta influencia habrian de tener luego en España, a cuya lengua son traducidos). Pero la existencia separada -y paralela- de la Ciencia de la Administración y del Derecho Administrativo, dura pocos años, puesto que este último termina adquiriendo una primacia inequivoca en las Universidades. Con la consecuencia de que la Ciencia de la Administración tiene que buscarse otros lugares de arraigo, concretamente en las escuelas para funcionarios.

Durante las décadas de 1820 y 1830 se suceden los proyectos de creación de Facultades de ciencias administrativas, preconizadas por Cuvier (1820), Macarel (1832) y Laboulaye, orientadas especialmente a la formación de funcionarios. Pero como todos estos proyectos fracasan por la decidida oposición de las Facultades universitarias de Derecho, durante la Segunda República se opta por la alternativa de una Escuela Administrativa, creada el 8 de marzo de 1848 , sobre bases similares a la Escuela Politécnica. Pero la institución tiene corta vida, tarada probablemente por su origen revolucionario y el radicalismo de sus profesores. En agosto del año siguiente es cerrada, sin más, por Luis Napoleón Bonaparte.

En las postrimerias del Imperio y, sobre todo, en la Tercera República renace la idea, que nunca llega a cuajar ni siquiera en un proyecto de ley. $Y$ es que la resistencia de las Facultades de Derecho 
Estudios

sigue siendo muy grande $\mathrm{y}$, además, los propios ministros ven con enorme recelo una institución que de alguna forma puede suponer una restricción a su facultad de elegir discrecionalmente a los funcionarios. $Y$, en fin, la materia pierde cada día prestigio, y aun consistencia, desalojada inexorablemente por el Derecho Administrativo, que responde con mayor fidelidad a la ideología de los tiempos.

Dentro de los grandes maestros de esta disciplina, hay, desde luego, algunos autores -como Duguit y Hauriou-, que pretenden insertar en el Derecho una veta extrajuridica, procedente de la ciencia política o de la sociología; pero es claro que ello nada tiene que ver con la vieja ciencia de la policía y muy poco, con la moderna Ciencia de la Administración, que con tantas dificultades se va incubando en Europa.

\subsection{ESPAÑA}

La situación española es verdaderamente singular a este propósito y sus peculiaridades no han sido suficientemente puestas de relieve. Porque sucede que entre nosotros la imitación del original francés es tan perfecta, que llega a desbordar las realizaciones del propio modelo.

Nuestros primeros autores de Derecho Administrativo, en efecto, prolongan la linea de la Ciencia de la Administración iniciada por Bonnin, cuando ya en el pais vecino se han extinguido sus últimos ecos. Tal como he indicado en otro lugar (Introducción a «34 articulos seleccionados de la Revista de Administración Pública con ocasión de su centenarion, 1984), Sainz de Andino, Gómez de la Serna, Javier de Burgos, Alejandro Oliván y, sobre todo, Ortiz de Zúñiga, exponen un Derecho Administrativo de carácter descriptivo, que se inspira confesadamente en las ideas y en los métodos de Bonnin, Vivien y Macarel; y, desde luego, las Lecciones de Derecho Administrativo de Posada Herrera constituyen una auténtica $-\mathrm{y}$ ciertamente magistral- exposición de Ciencia de la Administración.

Tendencia que se refleja igualmente en los proyectos de reforma universitaria. Concretamente, en el de 1841 se propone, nada menos, que la creación de una «Facultad nueva, que tomará el nombre de administrativa, en la cual se comprenderán los estudios necesarios a los que hayan de servir al Estado en todos los destinos públicos, civiles y administrativos. Transcurridos que sean los años que se prefijen para esta carrera, el Gobierno no podrá nombrar para ningún empleo civil o administrativo a ninguno que, no habiendo servido algún destino 
DA-1984, núm. 200. ALEJANDRO NIETO GARCIA. Los estudios sobre la Administración Pública: I...

antes de la promulgación de la presente Ley, no haya obtenido el grado de licenciado en la facultad administrativa».

Bien es verdad que el proyecto fracasa; pero no por los motivos que habian obrado en Francia sino, mucho más sencillamente, como consecuencia de la caida del Gobierno. Ahora bien, la Regencia de Espartero retoma la idea, canalizándola a través de una escuela especial, que se crea por Decreto de 29 de diciembre de 1842, es decir, varios años antes que en Francia.

Esta escuela estaba destinada a los funcionarios públicos, pues «la experiencia diaria acredita la necesidad de que se exijan estudios previos a los que han de desempeñar cargos importantes de la Administración pública». En ella se enseña el derecho politico; el internacional, la economía política, la Administración y el Derecho Administrativo; y en el articulo quinto del Decreto de creación se dispone que «desde el 1 de enero de 1845 los que de nuevo entren en la carrera de la Administración deberán acreditar su suficiencia en los estudios que se cursan en la escuela». Los estudios duraban dos años, con cursos desde el 15 de septiembre al 15 de junio, con clases diarias de dos horas, por la noche, para que pudieran asistir los funcionarios. Los exámenes serian por curso y uno final para la habilitación, al que podian presentarse los no avecindados en Madrid, de lugares en donde no exista escuela de Administración. Los funcionarios en activo, los graduados y cursantes de Jurisprudencia podian matricularse directamente en segundo curso, siendo posible estudiar "estas asignaturas simultáneamente con la facultad mayor. (Cfr., Mariano Peset: «Universidades y enseñanzas del Derecho durante las regencias de Isabel II», en Anuario de Historia del Derecho, 1969)

La vida de esta escuela fue también muy breve, pues no acertó a imponer su compatibilidad con las Facultades de Jurisprudencia. Ahora bien, entre nosotros nadie ha indagado todavia lo que en este proceso pudo haber influido -al igual que en Francia- la resistencia ministerial a dejarse imponer una institución, que inevitablemente había de coartar la discrecionalidad de los nombramientos funcionariales $\mathrm{y}$, más todavía, el régimen de botín o cesantia.

Sea como fuere, la Ciencia de la Administración no deja otra huella importante que la obra de Posada Herrera y el Derecho Administrativo domina absolutamente el panorama, aunque los planes de estudios universitarios dejen un margen relativamente importante a la descripción de la Administración pública y a su funcionamiento. 


\section{La irrupción de las teorías norteamericanas.}

La Ciencia de la Administración no cuenta en América con una tradición tan venerable como la europea, pero empieza a afirmarse desde finales del siglo pasado con una energia y una originalidad propias, que terminan exportándose a Europa masivamente, hasta tal punto que la bibliografia de este lado del Atlántico se ha convertido en su fiel tributaria.

Siguiendo en este punto a Chevallier y Loschak, (Science Administrative, I, 1978, pp. 33 y ss.), las teorias americanas se caracterizan por los siguientes datos, que contrastan con sus paralelos europeos: utilitarismo y pragmatismo, cuyo objetivo es determinar las reglas de una buena administración a partir de la experiencia; indiferenciación en el estudio y tratamiento de la Administración Pública y de las organizaciones privadas; $y$, en fin, escasa atención prestada al Derecho.

Por otro lado, dentro del complejo bibliográfico se pueden distinguir los siguientes bloques de actitudes: a) La que se interesa por las Administraciones públicas, con el fin de mejorar de alguna manera su funcionamiento: Es la que se inicia con W. Wilson, en 1887 , y se prolonga hasta la actualidad con nombres tan significativos como los F. Goodnow (bien conocido en España a través de Adolfo Posada), L. White, W. F. Willoughby, P. Appleby y, sobre todo, D. Waldo. b) La que se interesa exclusivamente por la gestión de negocios business management, que arranca de Taylor y que durante muchos años ha sido considerada como la teoria americana por antonomasia. c) La sociológica y psicosociológica, de impronta inequivocamente experimental, en la que se encuentran autores como E. Mayo, Merton, Gouldner y Selznick. d) Y la teoría de las organizaciones, que es la que mayores repercusiones e influencias ha ejercido en los paises europeos.

En cualquier caso, el estado de la ciencia americana ofrece un vivo contraste con el de la europea, en cuanto que alli ha tenido un desarrollo variado pero muy coherente, ha adquirido sin dificultades carta de naturaleza $\mathrm{y}$ reconocimiento social y universitario y constituye un ejemplo permanente para el resto del mundo. 
DA-1984, núm. 200. ALEJANDRO NIETO GARCIA. Los estudios sobre la Administración Pública: I...

\section{Situación actual.}

A diferencia de lo que sucede en los Estados Unidos, la ciencia de la Administración se debate aún en Europa en una crisis, que no consigue superar adecuadamente. Presionada por el Derecho Público, la Ciencia de la Administración no logra enraizar del todo en las Universidades, buscando, más bien, refugio en Escuelas especiales y de funcionarios, que sesgan gravemente sus objetivos. En los Estados Unidos también existe ciertamente esta duplicidad de lugares de estudio, que se simultanea en las Universidades (ordinariamente en las ramas de ciencia politica) y en escuelas especiales (como la Public Administration Clearinng House, de Chicago); pero tal duplicidad no significa indiferencia reciproca. La orientación de los estudios, dentro de sus innumerables variedades metodológicas, es sensiblemente única y los estudiantes, cualquiera que sea su procedencia, terminan ocupando puestos importantes de las Administraciones públicas y privadas.

En Europa, en cambio, la aludida duplicidad desemboca en indiferencia reciproca. A decir verdad, las enseñanzas de una y otra rama están más próximas a América que entre sí, puesto que confesadamente suelen desconocerse.

En Alemania sólo dos Universidades (Hamburgo y Colonia) han institucionalizado los estudios de este género, sin perjuicio de que en muchas Facultades se expliquen cursos de Ciencia de la Administración, pero siempre como consecuencia de la iniciativa y eventual vocación de los docentes. El centro de la investigación y de la enseñanza se encuentra en la Escuela Superior de Ciencias Administrativas de Spira, orientada fundamentalmente a la formación y perfeccionamiento de funcionarios, aparte de otras Academias territoriales y, sobre todo, municipales.

La misma compartimentalización existe en Francia entre las Universidades y la ENA, donde se mezclan, un tanto arbitrariamente, las actitudes teóricas y prácticas y las metodologias juridicas, politicas, sociológicas, económicas y aun filosóficas (Cfr., por todos, J. Chevallier y D. Loschak: Science administrative, 1978).

$Y$, en fin, idéntica es la situación en España, donde existen contadas cátedras universitarias de Ciencia de la Administración, que tradicionalmente ha venido enseñándose con un fuerte tinte juridico. Mientras que, por otro lado, ni el Instituto Nacional de Administración Pública 
ni el Instituto de Estudios de Administración Local han acertado a construir un cuerpo homogéneo de doctrina y ni siquiera han institucionalizado una enseñanza sistemática de la disciplina.

\section{EN BUSCA DE LA DIFICIL IDENTIDAD}

Hace relativamente poco tiempo descubrieron los autores americanos -no sin cierta sorpresa por su parte y, desde luego, con gran consternación de sus admiradores de todo el mundo- que la Ciencia de la Administración, de la que con buenos motivos tan orgullosos estaban, se encontraba atravesando una «crisis de identidad». De acuerdo con el irrecusable testimonio de Dwight Waldo La formación para la Administración pública en los años setenta, 1977, p. 20), «en los años cincuenta... la Ciencia de la Administración se mostraba muy incapaz, o al menós desinteresada, en abordar sus problemas centrales de construcción intelectual a la luz de las criticas que sufrió en la última posguerra. En los años sesenta esta situación continuó, y en los setenta se ha acentuado aún más, ya que el pensamiento administrativo fue recibiendo una masa de aportes cada vez más heterogéneos, pues cada vez era más amplio el conjunto de cosas que, según se creia, formaba parte de la Ciencia de la Administración o estaban relacionadas con ella. A esto hay que añadir el fracaso del intento que se hizo de llegar a un acuerdo acerca de la base intelectual de esta ciencia. Algunos escritores tomaron de la psicologia el concepto de crisis de identidad y lo aplicaron a esta disciplina, o tal vez subdisciplina o profesión, que llamamos función pública. La Ciencia de la Administración sufre, en efecto, una crisis de identidad, habiéndose expansionado enormemente en sus contornos, sin retocar, rehacer, ni forzar su núcleo»).

En rigor, sin embargo, se trata de algo más que de una crisis (que en este contexto implica la pérdida o quebrantamiento de algo que ya se tenía anteriormente), puesto que lo que de verdad sucede es que la Ciencia de la Administración nunca ha poseido tal identidad y lo nuevo de la situación presente es que ahora es cuando se ha tomado conciencia de ello y se ha magnificado la cuestión. A tal propósito, habría que buscar las raíces del problema en la base ideológica, que nunca se ha querido abordar con sinceridad, y que sesga todo su desarrollo; pero como de este tema ya me he ocupado con detenimiento en otro lugar 
DA-1984, núm. 200. ALEJANDRO NIETO GARCIA. Los estudios sobre la Administración Pública: I...

(cfr., Nieto: El pensamiento burocrático, 1976, pp. 631-791), basta ahora con hacer referencia a los aspectos internos.

Los estudiosos de la Ciencia de la Administación siempre han trabajado, por asi decirlo, por su cuenta, reflexionando sobre problemas y sobre técnicas de eficiencia y marginando un tanto las cuestiones de la calificación cientifica de su empeño. Gracias a esta despreocupación inicial, no exenta de arrogancia, se pudieron conseguir avances espectaculares en determinados aspectos de su estudio. Pero de esta forma resultaba inevitable el caer, tarde o temprano, en un cierto «complejo de inferioridad». Los empiricos y casuistas sintieron crecer sus ambiciones, pero cuando salieron del reducido ámbito de las empresas a cuyo servicio se encontraban, se percataron de la conveniencia, y aun de la necesidad, de firmar su posición en el universo de las ciencias.

Así es como surgen las primeras reflexiones, coloreadas de una ingenuidad casi propia del siglo XIX sobre si se estaba creando un arte o una ciencia; produciéndose con ello una especie de «enfermedad infantil», inevitable en la primera fase de todas las experiencias intelectuales nuevas.

Más adelante, cuando sus resultados se extendieron a foros internacionales, e incluso fueron recibidos en la Universidad, el problema se agudizó y la cuestión llegó a ser capital, puesto que de su solución dependía el afirmarse por derecho propio en los ámbitos cientifico y académico $o$, por el contrario, en mantenerse en una posición de segundo rango, como mera técnica instrumental. En su consecuencia, acrece la literatura sobre cuestiones principales y del tema inicial -simplista y secundario- de la calificación, o no, de ciencia, se pasa a otros más substanciales: la determinación del contenido y objetivos de la actividad, que es presupuesto lógico de la indicada calificación.

$Y$ es en este terreno, cabalmente, donde surge la «crisis» porque los autores, al intentar determinar su lugar preciso en el mundo de las ciencias, lo que descubren es que no saben exactamente lo que pretenden y ni tan siquiera lo que están haciendo. Constatación demoledora, pero que no podía sorprender a nadie que hubiera seguido con atención el curso de los acontecimientos.

$\mathrm{Y}$ es que la llamada Ciencia de la Administración se ha ido formando por agregación de elementos tan heterogéneos, que resulta muy dificil vertebrarlos en una unidad. Tal es el precio del sincretismo metodológico. El crecimiento desmesurado de la disciplina parecia haber reventado los moldes conceptuales antes de haber logrado su primera 
consolidación. A poco que se apuren las cosas, se demuestra la vaciedad de las calificaciones negativas: el hecho de que se estudie la Administración desde una perspectiva no juridica no garantiza la unidad de lo que se agrupa convencionalmente bajo tal bandera. Para escapar de esta contradicción lógica se hacen esfuerzos desesperados a fin de encontrar un hilo conductor y, si es necesario, se inventa teóricamente, como han hecho en Francia, con tan enorme agudeza como poco éxito, autores como Langrod, Bandet y Mehl, quienes pretenden haber encontrado en el «hecho administrativo» la roca firme que les sirve de cimiento para construir una sólida y «cientifica» Ciencia de la Administración (cfr., el Tratado de Ciencia Administrativa), dirigido por Langrod, especialmente las páginas 121 y siguientes de la edición española de 1973).

En definitiva, si la identidad se cuestiona como resultado de una ambición intelectual y práctica, que ha colocado bajo un mismo rótulo elementos heterogéneos y aun contradictorios, que no garantizan, antes al contrario, una mínima unidad temática, el mejor camino para encontrar -0 recobrar- esa identidad consiste en una depuración del repertorio de tales elementos. Lo que, en último extremo, supone proceder a un inventario de contradicciones, sean reales o aparentes, cuya clarificación resulta a todas luces imprescindible.

\section{El contenido: Administración Pública y organizaciones privadas.}

La primera cuestión, que a tal propósito surge, es la de si la Ciencia de la Administración se refiere únicamente a las Administraciones públicas o si también a las organizaciones privadas. Sobre ello han corrido rios de tinta, pero la enormidad de la trascendencia de la alternativa hace sospechar de inmediato que debe haber un malentendido inicial o que, dicho en otras palabras, la alternativa está mal planteada y que encubre un «falso problema».

La literatura americana señala a Wilson como iniciador de una Ciencia de la Administración referida también al Estado, conforme luego desarrolló, más minuciosamente, Leonard White. Este enfoque pudo parecer original, ciertamente, desde la perspectiva de un Taylor, quien inicialmente nunca había pensado en la Administración pública (aunque más por el objeto de sus análisis que por una decisión meditada, puesto que nunca negó la aplicación de su método a las Administraciones públicas, antes al contrario); pero implica un robinso- 
DA-1984, núm. 200. ALEJANDRO NIETO GARCIA. Los estudios sobre la Administración Pública: I...

nismo intelectual desmedido, puesto que en Europa la Ciencia de la Administración había nacido precisamente a la sombra del Estado. Sin necesidad de remontarse a la cameralista y a la ciencia de la policía -donde esta mentalidad se impone por definición- la «moderna» Ciencia de la Administración es una Ciencia del Estado, como ya había explicitado Romagnosi y así aparece sin excepción en todos los autores de la primera mitad del siglo XIX. Más aún: cuando esta ciencia se renueva en las postrimerias del siglo, lo que pretende es una profundización, un enriquecimiento -sociológico y político- del Derecho Administrativo (del Estado también por definición), al que se quiere hacer saltar más allá de la sombra de lo normativo.

Lo que sucede -y aquí está el secreto del mal planteamiento- es que Wilson está pensando en otra cosa: en algo que nada tiene que ver (aparte de la comunidad, absolutamente casual, del rótulo) con lo que se está haciendo en Europa. Con la advertencia, además, de que Wilson lo hace de una manera deliberada, puesto que es un universitario culto, que tiene referencias suficientes, aunque sean de segunda mano, de la cultura europea continental.

De donde resulta que, en el fondo, no se trata de determinar un contenido alternativo -con dos opciones distintas de una Ciencia de la Administración, sino de que han surgido dos ciencias de la Administración- la europea y la americana, que a fines del siglo XIX son completamente diferentes, insertas en mundos intelectuales separados por completo y que sólo tienen de común el rótulo.

Por ello, puede afirmarse que la polivalencia del rótulo había de introducir una confusión sencillamente devastadora, de la que no podrá salirse mientras no se aclare este punto. Wilson y sus seguidores -repetimos- están pensando en otra cosa: en un matiz de Ciencia Política y en unas técnicas de lo que luego habria de denominarse, genéricamente, «management». Pues bien, esto nada tenia que ver ni con von Stein ni con Duguit.

Aclarado esto, la cuestión puede plantearse de nuevo en unos têrminos más afinados: de lo que se trata, en definitiva, es de saber si existen determinadas técnicas -operativas o de comprensión- aplicables tanto a la Administración pública como a las organizaciones privadas, independientemente de que tales técnicas se hayan elaborado de ordinario al calor del estudio de las organizaciones privadas. Una pregunta que debe resolverse, rotundamente, en sentido afirmativo. 
Que la Administración pública es algo sustancialmente distinto a las organizaciones privadas, no puede ponerse en duda. Por citar, como ejemplo, a un solo autor, baste recordar que Cortiñas Peñáez Las Ciencias administrativas en América latina, Caracas, 1972, pp. 28 y ss.) ha dedicado muchas páginas al tema y sus argumentos -sin olvidar el tema de las posibles «convergencias»- son contundentes y hasta podrian completarse con otros datos. Pero esta diferenciación básica no excluye la existencia de elementos comunes, de la misma forma que el hombre y el roedor son seres zoológica y metafisicamente distintos y, sin embargo, presentan rasgos comunes tan intensos, que pueden ser estudiados simultáneamente. Los privilegios posicionales de la Administración pública y la separación de su régimen juridico respecto de las organizaciones privadas, no impide que los problemas de instalaciốn de sus oficinas o de su mecanización sean idénticos a los de éstas y que, por otra parte, instrumentos y figuras propios de las organizaciones privadas puedan ser perfectamente aplicables a la Administración pública, sin otro trabajo que el de adaptarse a las peculiaridades de ésta. Tal es, en el fondo, el auténtico problema que plantea el análisis del contenido de la Ciencia de la Administración, al menos desde la perspectiva en que ahora se está tratando.

En este sentido, las conquistas del management son aplicables a ambos tipos de organizaciones, en unos casos de forma literal y en otros, previa la correspondiente adaptación. Así es como debe entenderse la aludida postura de Wilson. Mientras que, por el contrario, la actitud de los Romagnosi, de los Bonnin o de los Hauriou no es transferible a las organizaciones privadas, cabalmente porque se trata de algo que nada tiene que ver con el management.

El pensamiento de Wilson, así interpretado, es el que inspira la práctica norteamericana de primeros del siglo y en iguales términos la correspondiente producción bibliográfica, que arranca de la temprana fecha de 1911, cuando F. A. Cleveland publica The Application of scientific management to the Activities of the State.

El tema, como es sabido, adquiere una singular importancia en los años treinta, cuando esta línea se recoge oficialmente por el presidente F. D. Roosevelt en el informe al Congreso (1937) conocido con el nombre de Report of the President's Commitee on Administrative Management (procedente de la llamada Comisión Brownlow), en el que pueden leerse párrafos tan significativos como el siguiente: «Un Gobierno sin un management es una casa construida sobre la arena. Los 
DA-1984, núm. 200. ALEJANDRO NIETO GARCIA. Los estudios sobre la Administración Pública: I...

Estudios

fundamentos del management eficaz, tanto en asuntos públicos como en privados, son bien conocidos. Han emergido universalmente donde quiera que los hombres trabajan unidos, en un objetivo común, sea o no a través del Estado, la Iglesia, las asociaciones privadas o las empresas comerciales. Están escritos en constituciones, estatutos y estipulaciones, y existen como hábitos de trabajo en la vida cotidiana de todo pueblo organizado.» $\mathrm{Ni}$ que decir tiene que esta actitud oficial repercutiria profundamente en la bibliografia. El tema se convierte en moda y por aquellos años se multiplican las obras sobre el mismo. Para comprobarlo basta recordar los nombres y las fechas de la edición de las obras de J. P. Hallihan: Administration of the Business as Gobernment, 1937; H. P. Hendall: Business Principles applicable to the public management, 1938; G. D. Balcok: Scientific management in Gobernment Operations, 1940, y tantos otros.

Racionalizando años más tarde este proceso, ha podido escribir F. C. Mosher (Democracy ant the Public Service, 1968, p. 71) que los presupuestos rectores de la Administración pública y de las organizaciones privadas «se incardinaban en una sociedad dedicada fundamentalmente al crecimiento y al progreso, en una filosofia de la racionalidad, en la fe en la ciencia y en el método científico... proclamando el evangelio de la nueva diosa de la eficiencias, cuya neutralidad política formaba parte del dogma y cuyos instrumentos técnicos -racionalidad, planificación, especialización, mediciones cuantitativas, estandarización y el principio del one best way- servian lo mismo para la Administración pública que para las organizaciones privadas.

\section{Los instrumentos}

Suele decirse que la Ciencia de la Administración se aproxima a la Administración con métodos no juridicos, mientras que el Derecho Administrativo lo hace con instrumentos puramente juridicos. Esta es, sin embargo, una verdad parcial, porque en rigor -es decir, cuando lo que se utiliza es el método estrictamente juridico- no existe una diferencia instrumental sino de objeto: asi concebido (y la metodología jurídica es la dominante en Europa durante muchos años) el objeto del Derecho Administrativo no es la Administración sino las normas juridicas administrativas. 
Ahora bien, cuando el Derecho Administrativo, abandonando escrúpulos metodológicos, pretende saltar por encima de las normas, o sea, cuando entra en cuestiones de eficacia y no de simple validez (como predicaron y practicaron juristas tan profundos como Duguit y Hauriou), entonces se borran las diferencias esenciales con la Ciencia de la Administración y lo que aparece en una diferenciación de grado. Porque la sociologia jurídica es una forma de management de la Administración Pública, de la misma forma que un management responsable no puede ignorar la incidencia de las normas jurídicas en el funcionamiento de todas las organizaciones sociales.

Con lo cual resulta que no es cierto que Derecho Administrativo y Ciencia de la Administración estén separados por el método, puesto que el método, una vez más, está condicionado por el objeto. Si se admite que el Derecho Administrativo no es solo una ciencia normativa sino también una ciencia de la realidad, hay que admitir también su parentesco substancial con el management. $Y$ si. se entiende que el objeto normativo no impide la integración y estudio de fenómenos secundarios, como es el de la eficacia real de las normas, habrá que entender que el estudio de tales efectos, en cuanto reales, es propio de la sociologia y, por ende, del management.

Por ello acaba de indicarse que la diferenciación no es de esencia sino de grado. El management -la Ciencia de la Administraciónenfatiza los aspectos no normativos, aunque no pueda llegar a desconocer los efectos normativos (juridicos); mientras que el Derecho Administrativo enfatiza los aspectos normativos, aunque también comprenda, siquiera sea marginalmente, los reales.

Porque en ambos casos el objeto es el mismo y los métodos utilizables también puedan ser comunes, sin perjuicio, claro es, de que algunos de ellos sean utilizados con preferencia inequivoca en cada uno de estos supuestos. En definitiva, pues, el resultado final de estas reflexiones es que Derecho Administrativo y Ciencia de la Administración no son actividades independientes sino complementarias. Tesis que, como veremos más adelante, tiene consecuencias muy importantes a la hora de examinar los estudios más idóneos para los directivos de la Administración Pública. 
DA-1984, núm. 200. ALEJANDRO NIETO GARCIA. Los estudios sobre la Administración Pública: I...

\section{CLASIFICACION DE OBJETIVOS}

Dentro del complejo de investigaciones y actividades, que se integran habitualmente en la Ciencia de la Administración, el primer objetivo que nos encontramos es inequívocamente cientifico, puesto que se refiere al conocimiento de la Administración, de su origen, estructura y funcionamiento. Aqui se trata de determinar las conexiones que median entre la organización, la sociedad y el poder, politico y de los demás órdenes, y de precisar sus relaciones externas e internas, analizando los correspondientes procesos de actuación, construyendo, incluso modelos tipicos, estructurales y funcionales, para detectar las desviaciones y disfunciones existentes, explicarlas y, en su caso, proyectarlas hacia el futuro en indagaciones prospectivas. Todo ello con materiales tomados de la realidad presente, debidamente contrastadas con su pasado histórico y los paralelos de otros países.

En este nivel la Ciencia de la Administración se superpone parcialmente con el Derecho Administrativo, en la medida que éste, como sucede ordinario (aunque sus autores no tengan siempre conciencia de ello) contemple las normas como un fenómeno social. Porque es el caso que los juristas actúan con frecuencia, sin saberlo, como sociólogos del Derecho (o como palitólogos y aun como políticos) y la Ciencia de la Administración es, en último extremo, una rama de la Sociología, tanto de la empírica como de la comprensiva; de la misma manera que también lo es la Ciencia Política. Afirmaciones que, en modo alguno, pretenden resucitar viejas polémicas, completamente inútiles, sobre finis regundorum del mapa de las ciencias. $\mathrm{Y}$ por otro lado -huelga también decirlo- estos objetivos cientificos pueden ser perseguidos con arreglo a los métodos, empiricos o abstractos, más variados.

El segundo objetivo es, por el contrario, rigurosamente utilitario; y, en cuanto tal, pueda considerarse como una fase posterior o consecuencia del anterior. La comprensión de los fenómenos no suele detenerse en el mero placer intelectual, o estético, de los investigadores, sino que, más tarde o más temprano, se traduce y concreta en una operación de incidencia social: queremos comprender para progresar o, lo que es lo mismo, porque queremos progresar tenemos que reflexionar previamente. 
DA-1984, núm. 200. ALEJANDRO NIETO GARCIA. Los estudios sobre la Administración Pública: I...

Estudios

En la Ciencia de la Administración siempre han coexistido tres corrientes de signo utilitario, sensiblemente convergentes y en parte superpuestas:

a) La primera de ellas se conoce ahora con el nombre de gestiología y comprende un repertorio de técnicas, deducidas de análisis previos que pueden ser muy rigurosos, enderezadas a un mejoramiento de la gestión administrativa y que van desde la iluminación de las oficinas a los procesos de decisión y participación, pasando por la simplificación y uso racional de la informática.

En este campo es donde se aprecia una mayor identificación de la Administración Pública y de las organizaciones privadas, puesto que la técnica suele poder ser aplicada indistintamente. Ahora bien, esta identificación nunca llega a ser absoluta, habida cuenta de que, como veremos inmediatamente, el interés público condiciona en casos la aplicación de determinadas técnicas, que distan mucho de ser neutrales a pesar de su apariencia.

b) La segunda de ellas es la reforma administrativa, entendida en este contexto no como una simple transformación esporádica -0 a todo lo más, periódica- de las estructuras, sino un permanente proceso de renovación, que también puede ser silencioso, tendente en todo caso a la consecución de una mayor eficacia y eficiencia, a una mejor adaptación al entorno político y social y a una más alta capacidad de respuesta a las exigencias exteriores e interiores.

Ni que decir tiene que este objetivo absorbe de hecho al primero, puesto que la reforma pasa por la utilización de técnicas de gestión, de la misma manera que las nuevas técnicas de gestión se integran en las organizaciones a través de una reforma. Ahora bien, la integración de técnicas nunca puede ser producida de manera automática, por cuanto la naturaleza pública de la Administración del Estado sesga indefectiblemente todas las importaciones ajenas. La razón politica prima sobre la razón técnica. Con lo cual se explica que muchos progresos técnicos, utilizados con éxito habitualmente en las empresas privadas, no puedan serlo -o lo sean de manera muy diferente- en la Administración Pública, dado que, sin esta precaución, podrian distorsionar los intereses públicos, la imparcialidad y la legalidad a cuyo servicio está sometida aquélla por imperativo de la norma constitucional. En el campo de la gestión de personal o de la contratación pueden encontrarse buenos ejemplos de lo que se está diciendo: el principio de la igualdad, 
DA-1984, núm. 200. ALEJANDRO NIETO GARCIA. Los estudios sobre la Administración Pública: I...

de rango superior, distorsiona aquí con frecuencia al de la eficacia, y por supuesto al del lucro, que son los motores fundamentales del sector privado.

c) Y en tercer lugar, intimamente relacionado con los anteriores, se encuentra la formación de administradores. Un extremo que, por razones del título del presente trabajo, merece un examen más detenido, aunque conviene ya adelantar que la enseñanza de esta ciencia nació como un factor complementario de la formación de funcionarios básicamente recibida en la Universidad, pero que también opera $-y$ el dato suele pasarse por alto en los análisis europeos- en el personal del sector privado. En los Estados Unidos el número de títulos otorgados por las escuelas de comercio y negocios es aproximadamente siete veces mayor que el de los concedidos en las escuelas orientadas a la formación de funcionarios. Tan es asi que, contra lo que pudiera creerse, menos del uno por ciento de los funcionarios han seguido cursos de Ciencia de la Administración. Más aún, «en realidad nunca ha existido la aspiración de poner los sellos de la Ciencia de la Administración a la inmensa mayoria de los funcionarios públicos» (D. Waldo: La formación... cit., páginas 47-48).

\section{FORMACION DE DIRECTIVOS}

Los servidores de la Administración Pública necesitan dominar una determina técnica, que puede ser rudimentaria, como en el caso de los ordenanzas, o especializada (mecanógrafas, conductores), sofisticada y objeto, incluso, de una profesión (arquitectos, médicos).

De ordinario, se supone que el funcionario domina la técnica, cuyo ejercicio le va a ser exigido, en el momento de su ingreso; por cuya razón la selección se limita a constatar la preexistencia de dicho dominio, a través del sistema de oposiciones y similares. Pero sucede que en algunos casos la técnica referida no es objeto de enseñanza previa, ni pública ni privada, fuera de la Administración; lo que provoca la necesidad de ser enseñada posteriormente a los seleccionados o, al menos, a los candidatos preseleccionados (Escuelas especiales de formación de funcionarios: por ejempleo, la Escuela Diplomática), como también es posible la formación permanente, llamada entre 
nosotros «perfeccionamiento» (al estilo de lo que se realiza en el Instituto Nacional de Administración Pública).

En todos estos casos se trata de técnicas no fungibles, es decir, de técnicas que o no se utilizan en el sector privado (como son las propias de la carrera diplomática o de aduanas) o que en el sector público precisan de una cierta especialización. Ahora bien, lo que a nuestros efectos interesa es que se trata de una sola técnica.

El problema estriba entonces en precisar si los directivos son capaces de ejercer su función con el dominio de una sola técnica o si precisan de una capacitación más integral.

En España se viene entendiendo tradicionalmente que basta con la primera solución, es decir, que basta con dominar una sola técnica para estar en condiciones de dirigir una unidad en la que se utilizan varias. En su consecuencia se entiende -y se practica- que un ingeniero agrónomo $\mathrm{o}$ un licenciado en derecho, que solamente conocen su técnica propia (aprendida incluso fuera de la Administración) pueden dirigir una unidd en la que sus subordinados han de manejar técnicas jurídicas, ingenieriles, económicas, presupuestarias, informáticas y de todo orden. Aunque bien es verdad que tambiên está previsto el adiestramiento posterior a través de cursos que justifican un «diploma de directivo»; lo que hasta ahora no ha pasado de meros ensayos no excesivamente felices.

En otros países, por el contrario, como es el caso del Reino Unido, se supone que el directivo no precisa de una técnica individualizada sino que basta con una madurez intelectual genérica, obtenida en la Universidad, que le capacita para adaptarse luego a las exigencias del servicio, indefectivamente variadas, aunque sólo sea por los traslados periódicos. Mientras que en otros países, en fin, como sucede en los Estados Unidos -donde la Ciencia de la Administración se encuentra en una situación de florecimiento privilegiado-, la enseñanza de funcionarios se debate en unas alternativas, que distan mucho de estar superadas: por un lado, la contraposición de técnicas generales y especializadas, puesto que en muchas Escuelas se da por supuesto que una formación generalista no sólo es imposible, sino además inútil; y por otro lado, el convencimiento de que la evolución científica es en este punto tan rápida que provoca en muy pocos años la obsolescencia de lo aprendido y obliga a una formación permanente. Sea como fuere, la tendencia dominante no aspira a una formación autosuficiente desde la Ciencia de la Administración, sino que, mucho más modestamente, 
DA-1984, núm. 200. ALEJANDRO NIETO GARCIA. Los estudios sobre la Administración Pública: I...

«las enseñanzas de esta disciplina son simplemente una parte de la preparación profesional de otro área de conocimientos, para obtener un simple titulo de diplomado, sin llegar a una verdadera licenciaturas (cfr. D. Waldo: La formación... cit. pp. 52 y ss.). En definitiva -resume este autor (p. 55)- «la Ciencia de la Administración no constituye ni puede constituir una disciplina, ni mucho menos una subdisciplina. Si así se concibiese, y asi lo hacen algunos, esta ciencia o habria muerto o se hallaría a punto de morir. La Ciencia de la Administración tiene por propósito fundamental la preparación para las carreras, ocupaciones y empleos, que poseen en general la mayor parte de los atributos sociológicos (en España, diriamos legales) que comporta la idea de una carrera en la función pública. Pero ninguna de las disciplinas particulares, aunque estén ya organizadas y tengan su propio nombre, es capaz de transmitir los conocimientos y la preparación básica para estas carreras. Por tanto, ninguna disciplina aislada, sino muchas disciplinas y materias en relación mutua y próxima han de prestar su contribución.»

Pues bien, en este contexto -y salvadas discrepancias y matizaciones- aparece lógicamente la Ciencia de la Administración como una posible fórmula de capacitación de directivos e incluso como una alternativa a la formación tradicional de carácter universitario. No obstante, para analizar debidamente el tema, resulta necesario seguir haciendo algunas precisiones.

Por lo pronto, es imprescindible indagar lo que la propia función de los directivos demanda. Con el agravante o dificultad de que el concepto de directivo es ambiguo: ni está fijado legalmente ni puede tampoco determinarse a priori, dada la variedad de sus tipos. En líneas generales puede describirse al directivo como: a) responsable de una unidad administrativa en la que se acumulan funciones y funcionarios heterogéneos; $b$ ) con facultades para determinar los objetivos concretos de la unidad dentro, claro es, de las lineas generales presupuestas en el momento de su establecimiento, y c) en situación de colaborar, junto con otros directivos de su mismo nivel, en la toma de decisiones propias de un nivel superior, ya inequívocamente político.

Vistas asi las cosas, podria considerarse a los directivos como el eslabón de engarce entre los políticos y los administradores, y a la función directiva como aquélla a la que corresponde la concreción e implementación de las decisiones políticas. Ahora bien, esta imagen sólo puede ser aceptada con una salvedad importante: la de que lo 
DA-1984, núm. 200. ALEJANDRO NIETO GARCIA. Los estudios sobre la Administración Pública: I...

politico y lo administrativo no son dos categorias reales distintas. Política y administración pueden ser, en el mejor de los casos, conceptualmente identificables; pero en la realidad se entreveran de forma tan sustancial que seria ilusorio pretender encontrar actividades politicas y administrativas absolutamente puras. Politica sin administración es una mera ficción intelectual. Por ello, mejor seria concebir el conjunto como un hilo continuo, que se desliza entre dos polos opuestos: la política y las realizaciones administrativas concretas; y dentro de este hilo se situarian, un tanto convencionalmente, los cargos determinados más o menos aproximados a cada polo, y de la misma forma a las actividades administrativas determinadas, cuyo lugar en el hilo no coincide necesariamente con el del cargo donde proceden, puesto que puntos muy próximos al polo politico pueden tomar decisiones muy próximas al polo administrativo, y viceversa. Sin olvidar, por otro lado, que la localización exacta de cada cargo depende de la situación histórica concreta; lo que significa que nunca puede ser estable. $Y$ asi pueden apreciarse con el transcurso del tiempo descensos o elevaciones muy sensibles del «partidor» entre lo político y lo administrativo. Con lo que se explica la dificultad de calificar los cargos que se encuentran en la zona intermedia, como es el caso de los directores generales.

Dicho esto, y volviendo al tema de la heterogeneidad de funciones y funcionarios, hay que tener en cuenta que la misma, aun siendo indiscutible, es tambiên susceptible de diferentes grados de especialización. La variedad de objetivos y funciones (más de éstas que de aquéllos, puesto que todas las funciones se supraordenan en un objetivo común) es la clave de la existencia de todas las unidades orgánicas, sean de construcciones escolares $u$ oficinas de presupuestos o de informática. Circunstancia que presupone, por naturaleza, una cierta especialización del correspondiente directivo; aunque debe quedar claro que esa «cierta especialización» no coincide nunca exactamente con la formación profesional estricta. En una unidad de construcciones escolares puede ser importante la arquitectura; pero dentro de ella actúan economistas, contables, juristas y docentes, entre otros muchos. Hasta tal punto que no suele ser arquitecto el director de la unidad, antes bien los arquitectos trabajan como especialistas dentro de ella.

Sin perjuicio de la especialización tendencial, lo importante del director 'es que esté en condiciones de dirigir -y por tanto de entenderlas actividades especializadas de sus subordinados. Tal es el secreto del 
DA-1984, núm. 200. ALEJANDRO NIETO GARCIA. Los estudios sobre la Administración Pública: I...

cargo. Con esta advertencia, a continuación va a examinarse hasta que punto se ofrece a los futuros directivos de la Administración Pública española la posibilidad de cumplir esta función.

En el sistema universitario español las técnicas más importantes, propias de la función directiva, se ofrecen de manera desarticulada y siempre en la inteligencia de que, al amparo de la «autonomia universitaria» y de la «libertad de cátedra y de investigación» -una y otra entendidas del modo más arbitrario- ni los planes de estudio de las Facultades y ni siquiera los programas de las asignaturas, garantizan el contenido de las disciplinas, que depende exclusivamente del talante personal o científico de los profesores:

a) En las Facultades de Derecho se estudia la técnica jurídica (y rudimentos de la económica y presupuestaria), que siguen siendo la clave de la capacitación de los directivos de una Administración empapada de legalidad. Pero tales estudios no se ofrecen de una manera selectiva -es decir, pensando en la Administración pública- sino con carácter general, aunque aceptablemente detallada.

b) En las Facultades de Ciencias Económicas se estudia la técnica de este orden, junto con rudimentos de la juridica y de la presupuestaria.

c) En las Facultades de Ciencias Empresariales se ofrece la gestiologia, incluida la contabilidad, al tiempo que rudimentos del derecho.

d) En las Facultades de Ciencias Políticas puede enseñarse alguna variante de la Ciencia de la Administración, al estilo que la entienda el profesorado, y en todo caso se analizan las estructuras politicas del Estado y de la Administración, asi como rudimentos del derecho. Y lo mismo puede suceder en Facultades de Sociologia.

e) Y, en fin, en las Escuelas Técnicas Superiores, además de aludirse a las técnicas juridicas y del más variado orden, y de estudiarse las matemáticas, existe la posibilidad de asomarse al mundo de la informática.

De esta forma, los directivos potenciales de la Administración pública (que proceden de la Universidad) ingresan con un bagaje técnico parcial, dependiente de la Facultad universitaria en que se han formado, y que completan luego con unos estudios sistemáticos que se les ofrece en el Instituto Nacional de Administración Pública. No hay, pues, una enseñanza funcional que capacite especificamente para el servicio de la Administración pública. 
Circunstancia que sugiere inevitablemente la tentación de establecer una enseñanza de esta naturaleza, que giraria sobre las siguientes técnicas, imprescindibles actualmente a un directivo, en cuanto que gracias a ellas puede entender, controlar $-y$, en definitiva, dirigir- a los componentes de una unidad administrativa: las jurídicas (Derecho Público y Administrativo), las presupuestarias y la informática, trabadas por un análisis básico de la estructura y relaciones del Estado y la Administración. Enseñanzas que podrian organizarse o bien dentro de la Universidad o bien en una Escuela especializada.

Tal sugerencia es admisible, desde luego, y hasta puede considerarse como necesaria. Pero la situación real de la enseñanza española $y$, más concretamente, la capacidad de su profesorado, impide su aceptación a la ligera.

La posibilidad de una escuela especializada ofrece, a primera vista, singulares ventajas, pueșto que sólo desde una Escuela propia puede la Administración atender a una demanda de necesidades, que únicamente ella conoce y, además, supone la plataforma para concentrar un profesorado, que reúna al tiempo los adecuados conocimientos teóricos y de experiencia que en estas enseñanzas son precisos.

Ahora bien, la förmula vale apenas como un desiderátum, como un horizonte todavia lejano, puesto que la Administración dista mucho de poder montar un servicio de estas características, como demuestran los repetidos fracasos experimentados hasta ahora en las Escuelas existentes. Por un lado, la mentalidad de los alumnos ofrece unas resistencias, que sólo podrán ceder con el transcurso del tiempo y en el supuesto de una profunda alteración del sistema funcionarial global. Mientras el alumno siga considerándose un funcionario, real o virtual, carecerá de interés por el aprendizaje. Y por otro lado, el estado rudimentario en que se encuentran en España los estudios de la Ciencia de la Administración impide desarrollar en estas Escuelas una enseñanza de la debida calidad, que sólo puede irse afirmando al cabo de los años. Por así decirlo, la Administración no está en condiciones de dar por sí misma el salto cualitativo que al efecto se necesita.

De aquí que la fórmula, aun siendo aceptable y deseable para el futuro, no parece que sea viable de momento. Mas realista parece, por el contrario, iniciar un camino, aparentemente más imperfecto, pero mucho más firme y, a la media o a la larga, más fructifero. Con ello nos estamos refiriendo al universitario. 
DA-1984, núm. 200. ALEJANDRO NIETO GARCIA. Los estudios sobre la Administración Pública: I...

La Universidad tampoco está en condiciones, ciertamente, de ofrecer una formación profesional aceptable para los directivos de la Administración pública; pero por su propia naturaleza institucional pueden sus profesores profundizar, al menos, en el estudio de la Ciencia de la Administración hasta alcanzar un nivel cientificamente satisfactorio.

Lo cual no habria de hacerse necesariamente dentro de un plan de estudios, oficial y rigido, sino, al calor de la flexibilidad que ha abierto la Ley de Reforma Universitaria, en enseñanzas especializadas y, sobre todo, en el tercer ciclo. De esta manera, la enseñanza podria ser relativamente profunda, en cuanto que no gravaria el currículum de los interesados en otras profesiones. $Y$ a los interesados en la Administración pública les proporcionaria el aliciente de adquirir un bagaje científico de calidad y, al tiempo, profesional y técnicamente rentable.

Planteadas asi las cosas, y una vez que, como acaba de recordarse, la förmula es ya legalmente posible, el obstáculo real seria encontrar un interés para que la Universidad montase estas enseñanzas, asi como la capacitación o especialización del profesorado. Dos obstáculos que pueden resolverse, sin embargo, conjuntamente, de manera harto sencilla, bajo el impuso de la propia Administración pública.

Tal como se ha indicado hace unos momentos, la Administración no está hoy en condiciones de montar sus propias Escuelas de alto nivel, y por ello ha de acudir al apoyo básico de la Universidad; pero sí que está en condiciones de fomentar el interés universitario, mediante una politica de conciertos, que estimule la afición científica y docente de los profesores más receptivos y de las Facultades más inquietas.

Porque, de toda evidencia, no se trata de lanzar al mercado un producto masivo de diplomas de Administración pública, que seria, incluso partiendo del ámbito universitario, de baja calidad y presumiblemente inútil para los estudiantes, sino de seleccionar algunos puntos de producción de ellos, que ofreciese garantías de esa ansiada calidad y utilidad. Y cabalmente aquí es donde entra en juego la Administración, que es quien puede estimular dicha actividad, e incluso regularla, mediante la indicada política de conciertos, que extenderia hasta donde fuera necesaria y fructífera, pero nada más. Con la ventaja adicional de que, a través de un concierto, puede la Administración aportar los medios de que la Universidad no siempre dispone, empezando por la experiencia del profesorado $o$, si se quiere, de profesores con experien- 
cia, que ahora ya son integrables en la estructura docente de la Universidad, una vez que ésta ha perdido su tradicional rigidez.

De esta manera, fortuna volente, a) se empezarian a sentar los cimientos de un estudio serio de la Ciencia de la Administración, desde una perspectiva de auténtica dignidad cientifica, a partir del núcleo de las actuales cátedras de Ciencia de la Administración; $b$ ) se proporcionaría un título o diploma, que sin llevar aparejada la condición de funcionario (lo que indudablemente le distorsionaria), no seria un simple papel para su poseedor sino que le colocaria en una posición de ventaja respecto de otros candidatos; $c$ ) la Administración contaria con una masa de candidatos, ya cualificados, sobre los que podría montar una formación posterior, no superficial ni de urgencia, sino auténticamente especializada y funcional; d) se racionalizaria el mercado de trabajo de altos funcionarios, al crearse un espacio regulado por la propia Administración, en cuanto que es ella quien domina absolutamente la oferta, pero que también influye en la demanda, tanto en la calidad como en la cantidad de los puestos de trabajo, y e) la enseñanza universitaria podría garantizar, además de la calidad, una base de neutralidad política, en cuanto que sólo es indirectamente influenciable por las presiones de la Administración.

En definitiva, aquí se sugiere una simbiosis entre la Universidad y la Administración, que se considera necesaria en la situación en que actualmente se encuentra España, donde ni la Universidad ni la Administración están en condiciones de resolver por si solas el problema. Una y otra han fracasado -si es que han llegado a intentarlo seriamente alguna vez- en la tarea de construir una Ciencia de la Administración (que de momento no existe ni en sus más mínimos rudimentos) y en el objetivo de que la misma, una vez fundada, sea útil para la formación de funcionarios directivos. Porque si se encomendase esta misión a la Universidad, es probable que ni siquiera lo intentase $\mathrm{y}$, en el mejor de los casos, produciria una ciencia inútil; y si la Administración la asumiese con sus solas fuerzas, estaria condenada de antemano al fracaso por falta de instrumentos. La implantación de una fórmula operativa es hoy posible, tanto desde dentro de la Universidad con el apoyo de la Administración, como desde fuera de ella, con los medios universitarios. Luego, si ello diera resultado, sería el momento de pensar en otras fórmulas institucionales más avanzadas.

Pero, en cualquier caso, hay que insistir que en modo alguno se está pensando en que así podrian hacerse directivos, puesto que lo único que 
se pretende es capacitar a ciertos individuos para que alguna vez lleguen a serlo. Los directivos no se «hacen» asistiendo a un curso, por muy afinado que sea; de la misma manera que hoy es ya muy dificil llegar a ser un buen directivo sin contar con una formación previa de determinado nivel. El tema de este trabajo ha sido, pues, el de la formación de futuros directivos, no el de su selección, que es algo muy distinto *

- Una vez escrito y entregado este artículo, ha aparecido en el número 100-102 (I) de la Revista de Administración Pública un trabajo de A. Gallego Anabitarte con el titulo de «Las asignaturas de Derecho político y administrativo: el destino del Derecho público españols (pp. 705-803), de tan singular importancia que su lectura debe recomendarse como complementaria a cuanto aquí se ha dicho, no obstante la diferencia de objeto de ambas aportaciones, dado que supone una descripción muy minuciosa y un análisis muy profundo de temas conexos, que actúan como telón de fondo de una misma problemática. Por cierto, que la admiración que siento por este autor y el respeto que me merece su deslumbrante trabajo no me impiden disentir de algunas de sus ideas centrales en unos términos, cuya explicitación y desarrollo no son propios de este lugar. 